\title{
Pilot implementation of the Curriculum "Promoting Learning Through Active Interaction (PLAI)" in a child with Sotos Syndrome
}

\author{
Sarris Dimitrios, Christodoulou Pineio, Christopoulou Foteini, Zaragas Harilaos, and Christopoulou \\ Eleni
}

\section{ABSTRACT}

The present study focused on the implementation of the PLAI Program in a boy with Sotos syndrome, aged 10 years. The aim was to describe the results regarding the communication skills of the child after the pilot implementation of the specific Curriculum. Video observation and analysis were used to assess the child's communication skills, both before and after the implementation of the program. The PLAI program, which was implemented for about 4 months, focused on improving the child's communication skills, included similar activities and was based mainly on the strategy of routine and sensory cues. The results from the implementation of the individualized educational program were quite satisfactory, as a significant improvement in the communication skills of the specific child was found. The contribution of the Curriculum "Promoting Learning Through Active Interaction" is very important for the education of students with severe-multiple disabilities.

Keywords: communication skills, PLAI program, Sotos Syndrome.
Published Online: December 27, 2020

ISSN: $2736-4534$

DOI : $10.24018 /$ ejedu.2020.1.1.17

Sarris Dimitrios

Assistant Professor of Special Education, Director of Laboratory Hall of Special and Therapeutic Education,

Department of Preschool Education, University of Ioannina, Greece

Christodoulou Pineio

PhD-Special Education

Christopoulou Foteini*

PhD Candidate, Department of

Preschool Education, University of

Ioannina, Greece

(e-mail: foteinichr007@gmail.com)

Zaragas Harilaos

Professor, Department of Preschool Education, University of Ioannina, Greece

Christopoulou Eleni

National and Kapodistrian University of Athens, Greece.

*Corresponding Author

\section{INTRODUCTION}

Sotos syndrome is a rare clinical entity of genetic etiology that causes physical overgrowth [1] during the first two to three years of life, usually accompanied by a delay in motor, cognitive and social development. This syndrome is also known as brain gigantism, due to the characteristic size and shape of the head. It was first described in 1964 by Sotos [24].

The clinical diagnostic criteria for Sotos syndrome can be summarized as follows:

- Overgrowth in the prenatal and postnatal period and especially in infancy [1], [5].

- Characteristic appearance of the face (upside down pear shape and usually hyperpigmentation of the skin) [1]. Children with this syndrome look more like each other than their siblings.

- Developmental delay: verbal [6], [7], motor [8] and cognitive [1], [9].

- Behavioral problems [10-12].

-Advanced Bone Age [13], [1], above the 90th percentile, as determined by an X-ray. That is, a birth with a body length over the 90th percentile. The head circumference is often above the 97th percentile position. As a result, in 100 children of the same chronological age, the child with Sotos syndrome has a larger head circumference than the other 97 children. Growth rate appears to decline during childhood or adolescence at the latest and the individual's final height tends to be within normal limits. Children with Sotos syndrome do not become "giants" [14]. Overgrowth observed in childhood does not continue into adulthood [14-16].

Of course, there are a number of other minor features that have been linked to Sotos syndrome. Emotional immaturity, dental problems (premature eruption of teeth, excessive wear, discoloration and gingivitis), ear infections, upper respiratory tract and urinary tract infections, heart problems [17-19], scoliosis [20], convulsions, kidney problems, hearing loss and vision problems [14], [18-19], [21-24].

More specifically, the symptoms of the Syndrome include a large and long head with a prominent forehead, large arms and legs-acromegaly from birth (an unusually increased 
distance between the eyes), slanted eyes, clumsiness, awkward gait, coordination problems [17], [25-26] unusual aggression and irritability [8-9], [22], [27-29].

At the same time, they usually have intellectual disability, learning difficulties and behavioral problems, such as attention deficit/hyperactivity disorder (ADHD), phobias, obsessions and compulsions, outbursts and impulsive behavior [2], [30-32]. Some children with Sotos syndrome present with autistic evidence [10], [12], [33] or give a complete picture of an autistic child [34-35].

Children with Sotos syndrome are usually taller and heavier than their peers. However, a child who looks older and acts more immature than his peers is at risk of low selfesteem, strained relationships with peers and family, and problems at school, because the expectations of the important others are higher than his potential [29], [36-37].

In later stages of childhood the gap begins to bridge. For many people, Sotos syndrome simply alters the timing of growth. Despite the initial trends, the adult suffering from Sotos syndrome is likely to be within the normal range of height and intelligence.

A small percentage (approximately 7\%) of children with Sotos syndrome will develop childhood cancer [38]. There is no single form of cancer associated with the syndrome [39].

Hypotension is present at birth in almost every child with Sotos syndrome. Muscle tone improves as the child gets older, but there are some adult cases in which the problem of hypotension still exists to some degree. Hypotension affects many aspects of a baby's development. It can cause difficulty swallowing and sucking, which usually lasts up to the first four months of a child's life. Hypotension makes it difficult to achieve fine and gross motor skills and the developmental milestones reported in these areas usually record a delay. Speech (as mentioned above) is also affected by hypotension and is typically defective [1], but as the child grows older and the hypotension subsides, speech improves.

Although the child may have developmental delays, severe mental retardation is rare. The IQ in people with Sotos syndrome according to Smith, 1988 (as reported by Agwu, et al., 1999), [14] ranges from 18-119, while according to other researchers ranges from 21-103 [33]. Furthermore, people with Sotos syndrome are prone to: a) language disorders (particularly expressive), b) speech production disorders, c) voice disorders, d) dysfunction (stuttering) and e) characteristics of average socialbehavioral realistic interaction [40-41].

\section{A. Frequency-Etiology}

The incidence of Sotos syndrome is 1: 10,000 to 1: 14,000 newborns. Many cases, however, have not been diagnosed, so this fact may put the epidemiological figures closer to 1: 5,000 .

Sotos syndrome is present in all races and genders. It is caused by mutations in the NSD1 gene [42]. The NSD1 gene normally provides instructions for carrying out a protein involved in the normal growth and development of the individual [25]. [43-44]. The complete absence of the NSD1 gene on chromosome $5 \mathrm{q} 35$ has been shown to cause
$50 \%$ of cases of the syndrome. In very few cases, autosomal dominant inheritance has been documented [1], [45].

\section{B. Diagnosis}

Sotos syndrome is often diagnosed months, even years after birth, after a slow process of constantly wondering if something is wrong. Usually, the diagnosis is made by observing a number of physical characteristics [34], such as bone age, facial features, muscle tone, developmental delay [1], but also in combination with a series of specialized laboratory tests, such as the analysis of chromosomes (can be done together with the test for the genetic syndrome of fragile $\mathrm{X}$ ) and the determination of bone age with X-rays.

Additional information for the diagnosis is provided by magnetic resonance imaging (MRI) of the brain. In the case of children with Sotos syndrome on MRI the following findings are usually observed:

-Excess fluid between the brain and the skull.

- Large bellies.

- Small or absent mesolobium.

- Small cerebellum.

- Normal brain size.

At the same time, because there are other genetic syndromes that cause overgrowth, a baby or child with growth acceleration should be thoroughly examined by an experienced physician specializing in overgrowth and genetic syndromes [46]. Sotos syndrome has many similarities to Wiedemann-Beckwith syndrome (Abraham, 1969, as reported by Rannke \& Bierich, 1983), [4], [9], [47].

There is no cure or method for preventing the syndrome. However, the symptoms can be effectively treated with the intervention of specialized therapists. For example, physical therapy can help restore muscle tone as much as possible, speech therapy can improve speech and so on.

\section{Curriculum "Promoting Learning Through Active Interaction"'- PLAI}

The PLAI curriculum is designed primarily for preschool or elementary school children with severe disabilities who have not yet developed a symbolic communication system and who have a very limited repertoire of communicative behavior [48].

The main goal of this curriculum is to develop step by step [49] intentional communication and active interaction based on reciprocity between the child and his educators, but also to all those involved in his education.

In particular, the objectives of the PLAI are defined as follows:

- Ability to develop a clear understanding of the child's already existing repertoire of cues, which is based mainly on the systematic observation and interpretation of his behavior in natural environments.

- Identify the child's choices, preferences and aversions, as well as the ways of communication that he uses.

- Increase the number and frequency of communication behaviors of the child. - Configuration of planned routines.

- Encourage the initiation of the communication action on the part of the child. - Use of stable and consistent communication signals by the "communication partner". 
- Establish social exchange during an activity and strengthen the interactive relationship between the educator and the child [48], [50].

Communication skills are very important for every child, but much more so for children with severe multiple disabilities, including children with Sotos syndrome, regardless of the etiology or generative cause. On the one hand, because the role they play in developing a relationship of trust between educator and child is crucial and on the other hand, because it is of particular importance for meeting the vital needs of the child. Usually, the communication behaviors (behavioral response, communication signals) of these children are rare, informal and often indistinguishable, ambiguous or contradictory in terms of their meaning by their educators and service specialists, so it is not possible to identify them, define them clearly, interpret them and reinforce them.

Most of the strategies described in the PLAI are strictly structured and require systematic observations, which are broken down into subcategories of forms of behavior. At the same time, such techniques must be adopted and included in the daily activities and routines that the child follows in all environments in which he works [48], [50].

The PLAI protocol consists of an interview with the child's educator to identify the child's recent communication skills and behaviors, which will form the basis for intervention planning, and five regulatory sections. Each section includes a basic reasoning, a general objective, guidelines for the educator-caregiver as well as general, specific objectives and suggested methods for implementation [48]. The first section deals with understanding the child's communication cues, the second with identifying the child's preferences, the third with establishing predictable routines, the fourth with establishing social exchange, and the fifth with encouraging the onset of communication.

The cues strategy is very important for the educational intervention in cases of children with severe - multiple disabilities. A cue is the constant matching of specific words, images and tactile or visual or auditory or olfactory or kinesthetic stimuli with each activity. The strategy of using systematic cues helps the child to develop a better and easier understanding of his world environment and helps to replenish areas that are deficient and which may be reduced vision, hearing loss or difficulty moving [48].

The constant correspondence of the cue and the circumstance is necessary in order for the child to understand the meaning of the cue. Different cues can be combined and used sequentially or simultaneously. There is not just one right way to use predictable cues. In some cases, the many different cues can be over-stimulating or confusing to the child. However, this can only be determined through trial and error and of course, through careful observation. In this case, only one cue at a time should be used [45], [48]. It is very important to individualize the cues each time depending on the case of the child and to choose the ones that the child responds best and are more accessible to him.

Also, a necessary condition for the successful outcome of the program is the consistency and continuity in the use of cues of the involved and interacting persons in the education of the child [51]. The program reflects a fusion of the principles, thoughts and perspectives of developmental psychology [48]. The transactional model (Sameroff \& Chandler, 1975, as reported by Chen et al., 1998; Klein et al., 2000), [48-49] and the concept of the child's "imminent development zone" (Vygotsky, 1978, as reported by Papamichael, 1988), [52] co-shape the theoretical basis for the PLAI program.

In addition, the user of the program should be familiar with the specific curriculum and should have the required background knowledge. The user should have knowledge of the typical development of children, the characteristics and developmental challenges associated with specific disabilities, as well as the ability to create effective relationships between family and the professional. The user must also be familiar with the various intervention principles and teaching strategies including the following: appropriate choice of steps, dependent reaction regarding the immediate response to the manifestation of communication behavior on the part of the child, dependent stimulus, significant stimulus feeding, goal facilitation, social exchange (reciprocity strategy), applied behavior analysis, project analysis, play, available extra time than is usually available to a child of typical development [48].

Given that the concepts of communication and interaction are very important for people with disabilities, the PLAI Curriculum builds on these concepts and supports its success in implementing routines and cues [48]. Routines are teaching strategies that help children understand the world around them and have a predictable schedule. They are enjoyable, simple, can be repeated often, allow for variations and at the same time enhance various forms of interaction [53]. The strategy of the routine is enhanced by the addition of sensory cues, in order for the child to identify and anticipate familiar activities. There is a clear signal that the activity begins, the steps are always done in the same sequence and in the same way everyone, the help provided is always given in the same way and to the extent needed each time with a tendency to minimize. And finally there must always be a clear signal that the activity is over.

The implementation of the PLAI program is based on repetitive facts that promote a predictable structure. When the child knows what will happen and what will follow, it is much easier for him to receive new information, but also to increase his participation [54]. The curriculum must be applied to natural events and the environments in which the child operates, because otherwise few families will use it. The intervention is built on the extension of existing strengths and does not focus on the child's shortcomings and also supports the efforts of educators which are based on natural expression [48], [55].

In summary, the PLAI program focuses on promoting the child's interaction with the general context of the family daily routine [48]. Communication achievement is a key goal for this program.

\section{Child Case Presentation-Brief Record}

Nick is a child with Sotos syndrome, 5 years old. He is studying for the second consecutive year in a kindergarten for children with mobility problems and multiple 
disabilities. The child's family history is the following. Nick was born with an IVF (In Vitro Fertilization) pregnancy second in a row. The mother was in bed during the first 3 months of pregnancy and was on medication. The duration of pregnancy was 38 weeks. The baby was born by caesarean section and with birth weight 3290 grams. Nikos stayed in the incubator of the hospital unit for a week, because he had respiratory problems. From the beginning, their doctors were concerned with the morphological physical development of the baby. This child got encephalitis at the age of two and was hospitalized in an intensive care unit. Today he suffers from convulsions and Sotos syndrome. When he has convulsions he has restless sleep. At the age of 3 he was hospitalized in a neurology department to control the tonic seizures he had.

Then, due to the unusual external characteristics of the child, the psychosocial retardation, the background and the imaging findings, an extensive laboratory test was started to determine the underlying disease-syndrome. There were strong signs of Sotos syndrome and the presence of metabolic disease was not ruled out. Thus, samples for genetic and metabolic testing were sent to specialized laboratories in Greece and abroad. Regarding the imaging control and based on the CT / MRI of the brain, it was found enlargement of the lateral abdomen and abnormality of their contour, reduction of the peritoneal white matter, medullary dysplasia, dolichocephaly, image of mild degree of peritoneal leukemia lesions. The radiological examination showed obvious kyphosis, deformity of $\Theta 12$, O1., short dysplastic the central part of the tributary ampho.

According to the psycho-emotional report prepared by the psychologist who attends the child, Nick has quadriplegia and his whole body is affected. He does not respond kinetically and cannot keep his head upright. Also, there is a lack of development of language skills and communication. He has severe mental retardation and severe emotional maturation problems. Nick is moved by his caregiver sitting in a wheelchair. He attends a program of speech therapy, occupational therapy and physiotherapy.

The socio-economic level of the family is low. The child's parents are very cooperative. The child's residence is surrounded by relatives who love Nick and accept him as well as the whole neighborhood. In his free time, Nick enters an upright position. He has corpus hypotonia and limb hypertension (image of spastic triangular). He has no salivation at all.

\section{E. Educational Evaluation}

Based on the educational evaluation which was prepared based on the Curriculum for children with severe mental disabilities [56] the following are observed:

Self-experience: Nick can experience his body through his skin. He perceives the various sounds and noises and reacts to them by turning his head to the source of the sound. He perceives visual, auditory and tactile stimuli. He has developed experiences of taste and smell. Its gross and fine mobility is not developed.

Self-care and body hygiene: Nick in this area is not at all autonomous. He accepts to be dressed, undressed and tries to help by shaking his hands. As for feeding, it does not show any autonomy. He can't use the spoon or the fork successfully. He can't drink water alone. As for the toilet, he is not self-served and wears a diaper.

Introduction to communication structure: Nick recognizes and reacts to stimuli. He is trained in the coordination of the senses. He has associated feel with touch. He shows objects he likes and seems to recognize some faces. The communication from Nick's side is non-verbal (smile, crying, uncoordinated hand clapping). When something does not please him, he does not strongly express his dissatisfaction, but avoids eye contact, indifferent. He responds with pleasure and shows a positive emotion to musical stimuli (rhythmic songs), mainly by sitting still and laughing, or by participating, hitting musical instruments as best he can.

Nick responds to human faces with a smile. He laughs when something pleases him and cries when he feels discomfort or pain. When his biosomatic needs are met, he feels comfortable, safe and happy. When given audiovisualsensory stimuli, he maintains contact and interaction with his social environment. Hearing his name does not always correspond. He gives the impression that he is not listening, but he responds whenever he wants and always subtly. He is not negative at work, but he needs a special approach in order to learn activities of the daily routine.

Introduction to the construction of mathematical thinking: Nick does not participate in the organization of space. Regarding time, Nick experiences the chronological sequence of daily situations.

Relationship and interaction with the environment: Nick is a very social child. He accepts the physical touch, the caress, the hug and in general the human contact as well as the presence of others. He is receptive to communication and easily conveys a positive feeling. He likes games that produce sound and are big and brightly colored.

Creation-expression: His handle is not functional, due to the serious health problems he presents. He tries and manages to hold objects and handle them, always in his own way. Nick, despite the fact that it is difficult to use materials and handicrafts, has gained experience with materials of the natural and artificial environment such as water, clay, plasticine, finger paints, bubbles, etc.

\section{OBJECTIVE AND NECESSITY OF THE STUDY}

The present study is a pilot application of the PLAI Curriculum in a case of a child with Sotos syndrome and aims to describe the results of this pilot application. There are no studies in the international literature that examine the effectiveness of the PLAI Curriculum [57] in children with Sotos syndrome.

Despite the fact that the area of communication and interaction of people with Sotos syndrome, but also of people with severe multiple disabilities in general is very important for the development of this population, in Greece no program has been developed to promote and enhance the interaction of specific individuals and their trainers. 


\section{METHODOLOGY}

The type of educational research chosen to be used in the present investigation is the case study, which is a very detailed study of an individual or a population. The case study captures unique characteristics, is easily understood by the general public and is closely linked to reality (Nisbet \& Watt 1984; as reported by Cohen, 2000), [58].

The intervention program focused on the process of feeding the child by the mother-educator. Capturing the development of the process of active interaction between the educator-mother and the child with Sotos syndrome could not be presented in a better way than just using the case study.

In the first phase, a meeting was held with the child's mother and a discussion took place in order to understand the purpose of the research. At the end of the discussion, her written informed consent was given and she agreed to participate herself and her child in the research. She agreed to the use of video recording, where this was deemed necessary and only for the purposes of this investigation. After the completion of the project, an agreement was reached to destroy the relevant material.

The use of video recording was intended to record the structure of the "food" activity, as well as a first recording of the child-trainer interaction and the cues already used by the mother-trainer. In particular, the functional assessment of the child was initially performed, which is considered particularly important for people with severe disabilities. Because it emphasizes the detailed identification of specific skills in the area of disability, which are needed for the development of the child's abilities as well as for the current levels of academic and functional performance, in order to design intervention strategies.

The steps followed in the case of Nick during the functional evaluation process can be summarized as follows: Creating a total list, evaluating the child's current functionality (using lists, discussing with parents, important others, student observation in the environments in which it works, interdisciplinary evaluation), prioritizing the child's needs to be taught, drafting the personalized intervention program [59].

More specifically, data on the child's communication behaviors, communication intentions, opportunities, and communication media, which formed the baseline, were collected through interviews with the mother, including the initial structured "Trainer Interview", as provided by the PLAI Curriculum, through the completed sheet of "Important Questions", but also through observation during the activities. The purpose of the "Instructor Interview" was to gather information about how Nick communicates, his learning style and his abilities and needs, while promoting a structure for discussion with the instructor. The interview was used as a basic measurement before the start of the Curriculum, to describe the child's reaction to external events and to describe the expression of emotions. The comparison of these data of the "Trainer Interview" before the beginning and at the end of the program helped to assess the effectiveness of the implementation of the PLAI Curriculum.

From the collection of the above data it emerged that the recognition of Nick's feelings and behavior is perceived through laughter, crying, the production of some sounds, facial expressions, eye contact, turning the head and body movements. It was found that Nick communicates more during the game. The mother was then videotaped while feeding the child, without any prior educational intervention (at the beginning of section 1, which was used as the initial assessment). It turned out that the mother-trainer usually used acoustic and tactile mainly hints. Other video recordings were then made during the completion, but also after the completion of the section of the program, which included the new cues as they were defined through the cooperation of the participants in the implementation of the PLAI program.

The implementation of the program started on November 15 and lasted for about 4 months. This research was made in a quiet space provided by the school for this purpose. Nick, his mother-trainer, the teacher and the curator of the kindergarten participated. The program aimed at specific behaviors for teaching through the strategy of routines and subroutines. The routines chosen for use were simple, and perspective. Nick was given the opportunity to make choices and have preferences in his own unique way. In order to achieve communication with Nick, the multi-sensory approach was followed. The teaching of communication skills was governed by the principle of maximizing appropriate communication, the principle of functionality, the principle of personalization and the principle of reciprocity. The technique of partial participation and the technique of motivation were used.

The child's choices and preferences were externalized through the alternative means of communication (pointing, pushing an object, articulating sounds, turning the head) that he had already mastered, but which until now was not given the opportunity to use them to the fullest. The video recordings that followed the original one had as their object the capture of the application of the new cues during the feeding of Nick, as defined by those involved in this effort. In this phase (formative evaluation) adjustments and modifications were already made to the educational environment based on the observations and measurements recorded in the initial evaluation.

The structure of the "food" activity after the inclusion of the new cues was organized as follows:

Acoustic cue: "Nick, food". We use a conventional keyword to signal the start of the activity.

Acoustic cue: lightly tap the plate with the spoon.

Tactile-objective cue: cleaning the child's hands with a damp cloth.

Visual cue: food photo. The food is on a red plate, placed on a white placemat, so that there is a color contrast and thus it is more easily perceived by the child.

Olfactory cue: "Nick, the food smells nice!"

Acoustic cue: "Raise your head high". We wait for a while and if he does not do it alone, we help him by saying: "Let's get up" and we help him to support his head in the stroller (kinesthetic cue).

Acoustic cue: "Nick, what do you want?". We wait for the child to give the picture of the food (if he does not give it, another acoustic cue is made: "do you want something?". And we urge him to give the corresponding picture with a verbal and physical suggestion. When the food is over we 
make an acoustic cue and ask "Did you finish the food Nick?". We wait for the child to push the plate in front of him.

Then follows an acoustic cue: "Nick, what do you want?" And we are waiting for him to give us the image of water. The water is in a blue glass, on a white placemat. If he does not give it, we make an acoustic cue and tell him "I do not know what you want". If he does not give it again, then the caregiver uses an objective cue, resting the glass of water in the child's mouth. The following is the acoustic cue: "Water". Then we ask: "Nick, do you want more water?" and wait for him to push the glass away from his mouth. The following is the acoustic cue "Nick, finish the food". Then, using an acoustic cue, we verbally reward the child by saying "Well done, Nick", but also by stroking his hand (tactile hint). Thus the child realizes the end of the feeding process.

From the way of using the above-mentioned cues it seems that the basic principle of these actions is the persistence and patience on the part of the trainer (implementation of the time delay strategy, which helps to encourage the initiation of communication behaviors on the part of the child).

The main part of the research are the various recording sheets, which correspond to the sections of the specific program and were completed by the research team through observation. Through the completion of the recording sheets of the Curriculum, the systematic observation of the child was achieved. This observation was supplemented by videotaping, which played an auxiliary-complementary role in making a more detailed description and observation of the behaviors of the child and its trainer and in confirming the results. The video recording achieved the recording of the child's progress after the implementation of the specific Curriculum. The video recordings were graded by each examiner - member of the research team separately, in order to eliminate the possibility of influencing the judgment of one examiner by another. Inter-rater reliability with the Kappa coefficient, which is basically a measure of agreement between the estimates of two different assessors [60]. The Kappa coefficient for the assessment agreement between the two examiners - assessors is .93 which shows a high level agreement.

At the end of the research, a final interview and a final video recording (final evaluation) was conducted with the mother-trainer of the child, in order to gather information regarding the use of communication strategies and the mother's experience from the implementation of the specific program. In this effort, during the assessments, measurements were made for the frequency of initiation of interactions and response to interactions on the part of the child, regarding the number of interactions and the type of cues. Interactions were recorded whenever a response and interaction occurred within the same interval or when an interaction was recorded in one interval and continued into the next [61].

\section{RESULTS}

The results obtained from the pilot implementation of the PLAI Curriculum led to the verification and confirmation of the connection of the research with the theoretical framework.

More specifically, in the research process, the educator recorded various forms of non-verbal communication behavior on the part of Nick. In addition, the importance of routines and cues (auditory, visual, kinesthetic, tactile, objective, and olfactory) was confirmed [28], [48], [59]. The use of routine and cues in the case of Nick, regarding the process of feeding led to positive results. Nick's mother stated after the implementation of the program that she learned to wait longer, during the interaction with her child. She also stated that she believes that her communication with the child has significantly improved and found that the eating process has become easier, more enjoyable for the child and shorter. Before the implementation of the program the feeding process lasted 20 minutes, while after the implementation of the program it was reduced to 12 minutes. After the implementation of the program, Nick showed that understands the sequence of steps and enjoys more the process of eating.

In the initial video recording, it is easy to see that the mother did not give the child enough communication opportunities during the feeding. She did not give him the opportunity to do what he could on his own and she did not wait for the child's reaction for as long as she should. It was found that the food and water were in front of the child from the beginning and thus he was not given the opportunity to ask for it in his own way. The child was also not given the opportunity to realize the beginning and the end of the meal. While, from the last video recording, it emerged that the mother-trainer gives the child the opportunity to take the initiative. Specifically, this can be seen from the point where the mother asks "What do you want, Nick?" and he gives her the image of food. As soon as the meal is over, Nick pushes the plate so that it is not in front of him. This marks the end of the meal. Then the mother asks "What do you want, Nick?" and the child gives her the picture with the water. In the end, the verbal and tactile reward is used and the child lifts his body a little and takes another place in his stroller.

The results of the measurements showed that the number (Graph 1) and the type of cues used by the trainer increased. The mother-trainer before the implementation of the PLAI program used 6 cues, while after the implementation of the program she used 17 cues of different types.

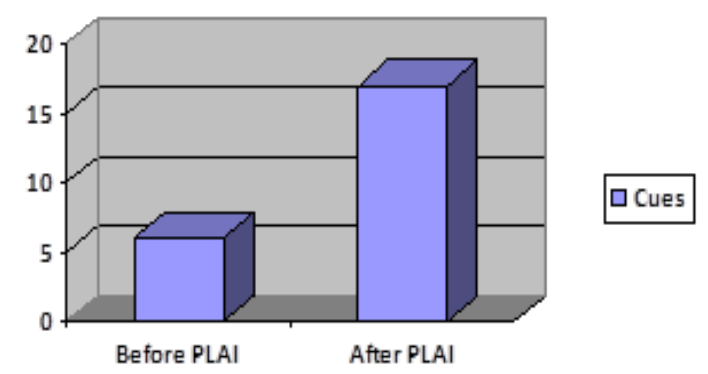

Graph 1. Number of cues used.

Regarding the type of cues used, the mother-trainer before 
the implementation of the program (as mentioned above) used only acoustic and tactile cues, while after its implementation included in her repertoire both visual and olfactory and objective, as well as kinesthetic cues. At the same time, it was observed that the frequency of initiation (Graph 2) and response to interactions on the part of the child (Graph 3) increased. Regarding the frequency of communication on the part of the child, it was observed that before the implementation of this program, Nick started communication only once during feeding, while after the completion of the program, he started communication four times.

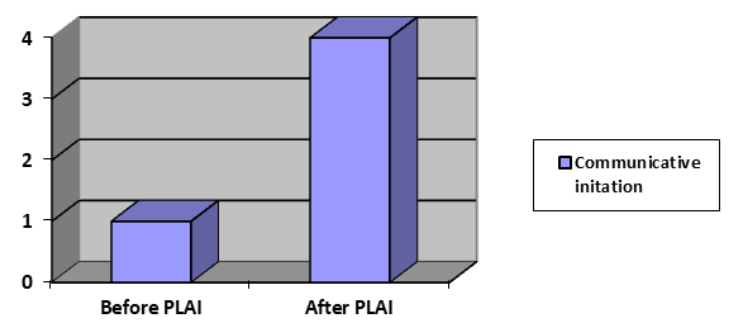

Graph 2. Frequency of initiation of communication by the child before and after the implementation of the program.

Regarding the frequency of response to the interaction, Nick before the application of PLAI responded to the interaction during feeding twice, while after the end of the program he responded six times.

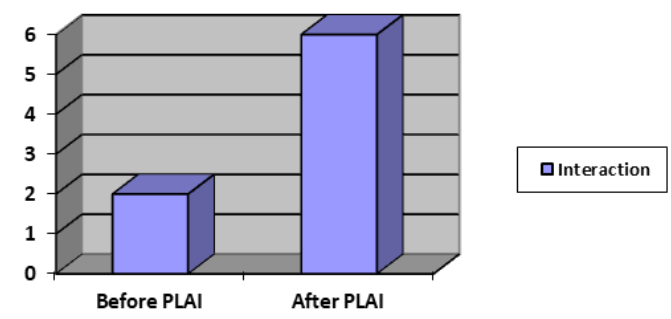

Graph 3. Frequency of interaction response by the child before and after the implementation of the program.

The results of the PLAI intervention program are also shown in the table below (Table 1).

TABLE I: RESULTS OF THE PLAI INTERVENTION PROGRAM

\begin{tabular}{lcc}
\hline \hline & $\begin{array}{l}\text { Before } \\
\text { PLAI }\end{array}$ & After PLAI \\
\hline $\begin{array}{l}\text { Cues (mother- } \\
\text { trainer) }\end{array}$ & 6 & 17 \\
$\begin{array}{l}\text { Communicative } \\
\text { initiation (child) }\end{array}$ & 1 & 4 \\
\hline $\begin{array}{l}\text { Interaction } \\
\text { response (child) } \\
\text { Duration of } \\
\text { feeding process } \\
\text { (minutes) }\end{array}$ & 2 & 6 \\
\hline \hline
\end{tabular}

\section{CONCLUSIONS-DISCUSSION}

The intervention based on the PLAI program emphasizes the child's existing abilities and focuses less on his weaknesses and shortcomings. It therefore supports the child's abilities and the efforts of the educator [57]. The results of the use of the program by its creators in a study conducted on a sample of 27 infants with multiple disabilities and their educators, were very encouraging in terms of communication behavior of educators and their interaction with the child. More specifically, the implementation of the program was evaluated as successful, because on the one hand it helped to teach educators to better support children's behaviors and on the other hand to involve children actively in daily activities and interactions [57].

At the same time, the literature review shows that there are research data that confirm the existence of positive results in people with multiple disabilities when they are given a choice (greater participation, increased interaction, higher level of performance), [62]. At this point it should be mentioned that the last part of the PLAI Curriculum is very important, because it focuses on helping the child to become a more active member in the interactions through the development of exchange games. The child learns how to develop specific communication skills. Although these communications will not necessarily be words, they will be clear and consistent. The key to learning is motivation. One of the best ways to encourage a child with multiple disabilities to communicate is to identify those things that are most interesting and important to him or her and that he or she prefers.

One way to determine the preferences of people with multiple disabilities is the technique of direct observation. An educator can offer opportunities to participate in activities to the student and an observer can record the student's interactions and reactions with the material offered [59].

The implementation of the program in the case of Nick was successful, because through the analysis, the study of the video recordings, and the study of the recording sheets, his progress was ascertained, in terms of his interactions and the communicative behavior with the mother-trainer. After the implementation of this program, Nick asks for food and water on his own initiative and pushes the plate with the food away from him, in his attempt to indicate the end of the food process.

The success of the program is mainly due to the fact that communication had a clear structure, consistency, repetition, and the fact that there was an obvious beginning and an obvious end to the feeding process. In addition, the child's pre-existing interactions and communication skills were taken into account during the design of the communication interventions (Olsson \& Granlud, 2003, as cited by Granlud \& Wilder, 2003), [63]. Furthermore, in this case the important role of routines and cues was confirmed [48].

In conclusion, this program can be effective in cases of children with similar potential, with some limitations of course, which do not allow the generalization of results. The fact that the case study is used as a methodology is itself a limitation. This program could be implemented effectively in cases of children with autism (low functionality), given the importance of routines for cases of children with disorders that fall within the range of autism. Because the PLAI program is flexible and can be adapted to the 
capabilities of each child, emphasizing on the existing communication framework.

The present study may be the impetus for further research and study. The findings are likely to create a fertile reflection and give a boost to the inclusion of this Curriculum in the education of children with multiple disabilities in Greece.

\section{ACKNOWLEDGMENT}

We would like to warmly thank Nick's parents for their participation in this research and their valuable cooperation.

\section{REFERENCES}

\section{(Periodical style)}

[1] Cole, P., Hughes, E. (1994). Sotos syndrome: a study of the diagnostic criteria and natural history. Journal Medical Genetics, 31:20-32.

[2] Mouridsen, E., Hansen, M.-B. (2002). Neuropsychiatric aspects of Sotos syndrome. A review and two case illustrations Journal of Medical Genetics 79:294-304.

[3] Sotos, F., Dodge, R., Muirhead, D., Crawford, D., Talbot, B. (1964).Cerebral gigantism in childhood: a syndrome of excessively rapid growth with acromegalic features and a no progressive neurologic disorder. Journal Medicine, 271:109-116.

[4] Baujat, G., Cormier-Daire, V. (2007). Sotos syndrome. Orphanet J Rare Dis, 2, 36 (2007). https://doi.org/10.1186/1750-1172-2-36

[5] Karlberg, J. \& Wit, M. (1991). Linear growth in Sotos syndrome. Acta Paediatr Scand 80:956-957.

[6] Bloom, S., Reese A, Hersh, H., Podruch, E., Weisskopf B., Dinno, N. (1983). Cognition in cerebral gigantism: are the estimates of mental retardation too high? Journal of Developmental and Behavioral Pediatrics 4:250-252.

[7] Boman, H., Nilsson D. (1980). Sotos syndrome in two brothers. Clinical Genetics 18:421-427.

[8] Sobel, E. (1995).Cerebral gigantism (Sotos' syndrome). A rare cause of delayed walking and awkward gait. Journal of the American Podiatric Medical Association, 85, 9 497-499.

[9] Ranke, M. \& Bierich, J. (1983). Celebral gigantism of hypothalamic origin. European Journal Pediatric, 140, 109-111.

[10] Varley, K., Crnic, K. (1984). Emotional, behavioral, and cognitive status of children with cerebral gigantism. Journal of Developmental and Behavioral Pediatrics 5: 132-134.

[11] Wit, M., Beemer, A., Barth, L., Smith, M., Sitarenios, G. (1994). Language and behavior in children with Sotos syndrome. Journal of the American Academy of Child and Adolescent Psychiatry 33:13071315

[12] Rutter, C., Cole, P. (1991). Psychological characteristics of Sotos syndrome. Developmental Medicine and Child Neurology 33:898902.

[13] Rao, H., Buehler, A., Schaefer, B. (1998). Accelerated linear growth and advanced bone age in Sotos syndrome is not associated with abnormalities of collagen metabolism. Clinical Biochemist, 31:241249.

[14] Agwu, C., Shaw J, Kirk J., Chapman S., Ravine, D., Cole P. (1999). Growth in Sotos syndrome. Archives Diseases Child, 80:339-342.

[15] [Chen C-P., Lin S-P., Chang T-Y, et al. (2002). Perinatal imaging findings of inherited Sotos syndrome. Prenatal Diagn, 22:887-892.

[16] Cole, P., Hughes, E. (1990). Sotos syndrome. Journal Medical Genetics, 27:571-576.

[17] Foster, A, Zachariou, A, Loveday, C, et al. (2019). The phenotype of Sotos syndrome in adulthood: A review of 44 individuals. Am J Med Genet Part C, 181C: 502- 508. https://doi.org/10.1002/ajmg.c.31738

[18] Maino, M., Kofman, J., Flynn, F., Lai, L. (1994). Ocular manifestations of Sotos syndrome. Journal Am Optom Assoc., 65:339-346.

[19] Nagai, T., N. Matsumoto, N. Kurotaki, N. Harada, N. Niikawa, T. Ogata, K. Imaizumi, K. Kurosawa, T. Kondoh, H. Ohashi, M. Tsukahara, Y. Makita, T. Sugimoto, T. Sonada, T. Yokoyama, K. Uetake, S. Sakazume, Y. Fukushima, K. Naritomi, . (2003). Sotos syndrome and haploinsufficiency of NSD1: clinical features of intragenic mutations and submicroscopic deletion, J. Med. Genet. 40 (2003) 285-289.
[20] Haga, N., Nakamura, S., Shimode, M., Yanagisako, Y., Iwaya, T. (1996). Scoliosis in cerebral gigantism, Sotos syndrome. Spine 21:1699-1702.

[21] Kamimura, J., Endo, Y., Kurotaki, N., Kinoshita, A., Miyake, N., Shimokawa, O., Harada, N., Visser, R., Ohashi, H., Miyakawa K., Gerritsen, J., Innes, M., Lagace, L., Frydman, M.,. Okamoto, N., Puttinger, R., Raskin, S., Resic, B., Culic, V., Yoshiura, K., Ohta, T., Kishino, T., Ishikawa, M., Niikawa, N., Matsumoto, N. (2003). Identification of eight novel NSD1 mutation in Sotos syndrome, Journal. Medicine Genetics, 40126.

[22] Ambler, G. (20020. Overgrowth, Best Pratice Res. Clinical Metabolism, 16, (3), 519-546.

[23] Noreau, R., Al-Ata, J., Jutras, L., Teebi, S. (1998). Congenital heart defects in Sotos syndrome. Am Journal Medicine Geneics, 79:327328.

[24] Tsukahara, M., Murakami, K., Iino, H., Tateishi, H., Fujita, K., Uchida, M. (1999). Congenital heart defects in Sotos syndrome. Am Journal Medicine Genetics, 84:172.

[25] Brown, J., Jawad, M., Twigg, F., et al. (2002). A cryptic $(5 ; 11)(\mathrm{q} 35 ; \mathrm{p} 15.5)$ in 2 children with acute myeloid leukemia with apparently normal karyotypes, identified by a multiplex fluorescence in situ hybridization telomere assay. Blood; 99:2526-2531.

[26] Smith, A., Farrar, R., Silink, M., Judzewitsch, R. (1980).Dominant Soto's syndrome. Archives Disease Child, 55, 7, 579.

[27] Fagali, C., Kok, F., Nicola, P., Kim, C., Bertola, D., Albano, L., Koiffmann, C. (2009). MLPA analysis in 30 Sotos syndrome patients revealed one total NSD1 deletion and two partial deletions not previously reported. European Journal of Medical Genetics, 52, 333336.

[28] Tatton- Brown, Rahman N. (2004). Clinical features of NSD1positive, Sotos syndrome. Clinical Dysmorphol., 13, 199-204.

[29] Cole, P., Hughes, E. (1990). Sotos syndrome. Journal Medical Genetics, 27:571-576.

[30] Lane, C., Milne, E., Freeth, M. (2016). Cognition and Behaviour in Sotos Syndrome: A Systematic Review. PLOS ONE, 11(2): e0149189. https://doi.org/10.1371/journal.pone.0149189

[31] Sheth, K., Moss, J., Hyland, S., Stinton, C., Cole, T., Oliver, C. (2015). The behavioral characteristics of Sotos syndrome. Am J Med Genet Part A, 167A: 2945-2956.

[32] Tatton-Brown, K., Cole, TRP, Rahman, N. (2004). Sotos Syndrome. [Updated 2019 Aug 1]. In: Adam MP, Ardinger HH, Pagon RA, et al., editors. GeneReviews ${ }^{\circledR}$ [Internet]. Seattle (WA): University of Washington, Seattle; 1993-2020. Available from: https://www.ncbi.nlm.nih.gov/books/NBK1479/

[33] Finegan, K., Cole, P.,Kingwell, E.,Smith, L., Smith, M., Sitarenios, G. (1994). Language and behavior in children with Sotos syndrome. Journal of the American Academy of Child and Adolescent Psychiatry 33:1307-1315.

[34] Opitz, M., Weaver, W., Reynolds, F. (1998). The syndromes of Sotos and Weaver: reports and review. American European Child \& Adolescent Psychiatry 11:43-48.

[35] Morrow, D., Whitman, Y., Accardo, J. (1990). Autistic disorder in Sotos syndrome. A case report. European Journal of Pediatrics 149:567-569.

[36] Dodge, R., Holmes, J., Sotos, F. (1983). Cerebral gigantism. Developmental Medicine and Child Neurology 25: 248-252.

[37] Livingood, B., Borengasse, A. (1981). Cerebral gigantism in infancy: implications for psychological and social development. Child Psychiatry and Human Development 12:46-53.

[38] Wit, M., Beemer, A., Berth, G. et al. (1985). Cerebral gigantism (Sotos syndrome): compiled data on 22 cases. European Journal Pediatric, 144, 131.

[39] Visser, R., Matsumoto, N. (2003). Genetics of Sotos syndrome. Curr Opin Pediatr 15:598-606.

[40] Lane, C., Herwegen, V. J., Freeth, M. (2019). Parent-Reported Communication Abilities of Children with Sotos Syndrome: Evidence from the Children's Communication Checklist-2. Journal of Autism and Developmental Disorders, 49, 1475-1483. https://doi.org/10.1007/s10803-018-3842-0

[41] Ball, L.J., Sullivan, M.D., Dulany, S., Stading, K. and Schaefer, G.B. (2005), Speech-language characteristics of children with Sotos syndrome. Am. J. Med. Genet., 136A: 363-367. https://doi.org/10.1002/ajmg.a.30799

[42] Kurotaki, N, Imaizumi, K, Harada, N., et al. (2002). Haploinsufficiency of NSD1 causes Sotos syndrome. Nat Genet;30:365-366.

[43] Panarello, C., Rosanda, C., Morerio, C. (2002). Cryptic translocation $\mathrm{t}(5 ; 11)(\mathrm{q} 35 ; \mathrm{p} 15.5)$ with involvement of the NSD1 and NUP98 genes without $5 \mathrm{q}$ deletion in childhood acute myeloid leukemia. Genes Chromosomes Cancer 35:277-281. 
[44] Jaju, J., Fidler, C., Haas, A., et al. (2001). A novel gene, NSD1, is fused to NUP98 in the $\mathrm{t}(5 ; 11)(\mathrm{q} 35 ; \mathrm{p} 15.5)$ in de novo childhood acute myeloid leukemia. Blood, 98:1264-1267.

[45] Winship, I. (1985). Sotos syndrome-autosomal dominance inheritance substantiated. Clinical Genetics, 28, 243-246.

[46] Amiel, J., Faivre L., Wilson L., et al. (2002). Dysmorphism, variable overgrowth, normal bone age, and severe developmental delay: a "Sotos-like" syndrome? Journal Medical Genetic 39:148-152.

[47] Douglas, J., Hanks, S., Temple, K., et al. (2003). NSD1 mutations are the major cause of Sotos syndrome and occur in some cases of Weaver syndrome but are rare in other overgrowth phenotypes. Am Journal Human Genetics, 72:132-143.

[48] Klein, D., Chen, D., Haney, M. (2000). Promoting Learning Trough Active Interaction: A guide to Early Communication with Young Children Who Have Multiple Disabilities. Baltimore: Paul H. Brooks Pub.

[49] Chen, D., Haney, M., Klein, D., Alsop, L. (1998).Learning How To PLAI: Ways To Promote Learning through Active Interaction with Infants Who Are Deafblind. Canadian Conference on Deafblindness (6th, Mississauga, Ontario, Canada, August 12-15, 1998).

[50] Kartasidou, L. (2008). Models of education for students with severe multiple disabilities: Enhancing interaction and communication. University notes, Thessaloniki.

[51] Demchak, M., Richad, C., Elquist, M. (2001). Providing cues to enhance receptive communication. News Letter, 12, 2.

[52] Papamichael, G. (1988). Learning and society: Education in theories of cognitive development. Athens: Odysseus.

[53] Reichle, J. (1997). Communication intervention with persons who have severe disabilities. The Journal of special education, 31 .

[54] Smith, A., Farrar, R., Silink, M., Judzewitsch, R. (1980).Dominant Soto's syndrome. Archives Disease Child, 55, 7, 579.

[55] McColllum, A. \& McBride, L. (1997). Ratings of parent-infant interaction: Raising questions of cultural validity. Topics in Early Childhood Special Education, 17, 4, 494-519.

[56] Ministry of National Education and Religions, Pedagogical Institute, Department of Special Education (2003). Interdisciplinary Unified Curriculum Framework and Compulsory Education Curricula for the education of children with severe mental retardation.

[57] Chen, D., Klein, D., Haney, M. (2007). Promoting interactions with infants who have comlex multiple disabilities: Development and Field-testing of the PLAI curriculum. Infants \&Young Children, 20, 149-162.

[58] Cohen, L., Manion, L., Morrison, K. (2000). Educational research methodology. Metaichmio, Athens.

[59] Sipani, E. \& Spooner, F. (1994). Curricular and instructional approaches for persons with severe disabilities. Allyn and Bacon.

[60] Howitt, D., \& Cramer, D. (2001). Statistics with SPSS 10 for Windows. Athens: Kleidarithmos.

[61] Lee, S. \&Odom, S. (1996). The relationship between stereotypic behavior and peer social interaction for children with severe disabilities. Journal of the association for persons with severe handicaps, 21, 88-95.

[62] Houghton, J., Bronicki, B., \& Guess, D. (1987) Opportunities to Express Preferences and Make Choices among Students with Severe Disabilities in Classroom Settings. The Journal of the Association for Persons with Severe Handicaps, 12(1), 18-27.

[63] Wilder, J. \& Granlund, M. (2003). Behaviour style and interaction between seven children with multiple disabilities and their caregivers. Child: Care, Health and Development, 29,6, 559-567. 